\title{
Structural Inequalities and
} \section{Intersectionality are the Root Causes} of Gender Discrimination \& Sexual

\section{Harassment}

\author{
What does this mean for the Healthcare Workplace?
}

\section{ABSTRACT}

Sexual harassment and gender discrimination overlap affecting people (including children) of all genders, however data shows an overwhelmingly high prevalence of violence or harassment experienced by women in areas of conflict, professional life and in their homes as well as in the healthcare workplace. It is pervasive, persistent and all too common.

Workplace sexual harassment an discrimination although illegal, is particularly is more common in women who are young, early in their careers, in temporary employment, from under-represented or marginalised groups based on ethnicity, immigrant status, gender non-conformity or disability. Majority of perpetrators are men, who are older and enjoy the privilege of disproportionate power and in certain toxic male-dominated healthcare environments.

Two recent stories of sexual harassment in healthcare prompted many women to follow suit and share similar stories referring to flashbacks, post-traumatic stress, damage to careers, pressure to leave their job, self-harm and suicidal thoughts, brought about by their experiences. Yet there are examples of women as role models breaking down historical barriers such as Hilary and Chandi in their polar adventures.

Tackling such structural inequality requires remedies that go beyond incremental approaches focussed on individuals and include transformation of the organisational and societal climate by interventions, affirmative policies and courageous, compassionate leadership. Workplace sexual harassment and discrimination is unacceptable, not inevitable and needs to be eradicated.

Keywords

Sexual harassment, gender discrimination, workplace dignity
Priyanka Nageswaran 1 , Mahua Chakrabarti², Nagina Khan ${ }^{3}$, Neena Modi $^{4}$, Vipin Zamvar ${ }^{5}$ \& Indranil Chakravorty 6

1 Academic Digital Fellow, Imperial College School of Medicine, London

2 Consultant General Surgeon, Lanarkshire, Scotland \& Vice-Chair, BAPIO Women's Forum 3 Senior Research Associate, University of Touro Nevada, USA

4 Professor of Neonatal Medicine, Imperial College London

5 Cardiothoracic Surgeon, Edinburgh Royal Infirmary, Scotland

6 Professor, Life \& Medical Sciences, University of Hertfordshire \& St George's University Hospital, London

Correspondence to indranil.chakravorty@nhs.net

Cite as: Nageswaran, P., Chakrabarti, M., Khan, N., Modi, N., Zamvar, V., Chakravorty, I. (2022) Structural inequalities and intersectionality are the root causes of gender discrimination \& sexual harassment. Sushruta J Health Pol \& Opin vol 15; Issue 1: ePub 24.1.22 DOI https://doi.org/10.38192/15.1.4

Article Information

Submitted 23.1.22

Pre-print 24.1.22

ISSN 2732-5164 (Online) ISSN 2732-5156 (Print)

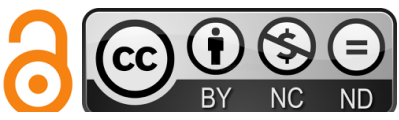




\section{Background}

During the transition from 2021 to 2022, two very distinctive and disparate stories caught our attention. These stories found themselves circulating energetically on the social media platform Twitter. The first, was one of a colossal achievement by Captain Preet Chandi (Twitter @PreetChandi10) of the British Army, who walked unaccompanied, a gruelling 700 miles in 40 days, in temperatures as low as $-50^{\circ} \mathrm{C}$, to reach the South Pole. This made her the first woman of South Asian origin to accomplish this feat and an allied health professional (physiotherapist). It has been over 100 years since the first AfricanAmerican, Matthew Henson, reached the North Pole in 1909 [1] and in 2007, Barbara Hillary, became the first African-American woman to set foot on the geographical North Pole. Four years later Hilary also became the first AfricanAmerican to reach the South Pole.[2] Captain Preet Chandi has become an inspirational role model and demonstrated a great personal victory at a time when the healthcare workforce is particularly battered from the multiple surges of a global pandemic.

Concurrent to this story of great accomplishment, comes another of disillusion and disgust, one that like the former, diffused rapidly through social media. It is a letter written by Philippa Jackson in response to an article by Fleming and Fisher [3] discussing the painful truth of sexual assault in the surgical specialties. Philippa Jackson, now a Consultant Plastic Surgeon, responded to Fleming and Fisher with accounts of her harrowing personal story as a junior doctor that was filled with inappropriate sexual advances, poor leadership, immoral and cowardly behaviour from those who were aware and an inexcusable lack of support for someone who chose to speak up [4]. This story prompted many women to follow suit and share their experiences referring to flashbacks, post- traumatic stress, damage to careers, pressure to leave their job, self-harm and suicidal thoughts. Each individual story is yet another argument to strive for a culture that has a zero tolerance approach to sexual harassment and abuse. Although starkly different in their tones, there is a significant similarity in both stories; a high achieving woman bravely breaking down a barrier, overcoming a hurdle and positively changing the norm.

In this article, we will explore the emotional arena of workplace sexual harassment as experienced in the health service and seek solutions.

\section{Prevalence}

Sexual harassment or violence is widely prevalent. Although it may take a variety of forms and affect women, men, children and people of non-binary genders, and is often underreported the prevalence of violence against women is the most frequent, affecting more than 1 in 3.[5] Sexual harassment is defined as a sexual advance, request for sexual favours, or other conduct of a sexual nature that is unwelcome, unsolicited, and makes the recipient feel harassed, upset, scared, offended or humiliated.

To understand and unravel sexual harassment, one has to tackle the overlapping issue of gender discrimination. Gender refers to the characteristics of women, men, girls and boys that are socially constructed norms, behaviours and roles, as well as relationships with each other. It is understood that gender interacts with but is different from sex, which refers to the different biological and physiological characteristics of females, males and intersex persons. Gender and sex are related to but different from gender identity. Gender identity usually refers to a person's deeply felt, internal and individual experience of gender, which may or may not correspond to the person's physiology or designated sex at birth.[6] 
The Sex Discrimination Act 1975 [7] makes sexual harassment unlawful in public life, including employment, while sexual assault is a criminal offence. Sexual harassment (as a form of discrimination) is conceptually distinguished into certain types of behaviour:

(1) gender harassment (verbal and nonverbal behaviours that convey hostility, objectification, exclusion, or second-class status about members of one gender),

(2) unwanted sexual attention (verbal or physical unwelcome sexual advances, which can include assault), and

(3) sexual coercion (when favourable professional or educational treatment is conditioned on sexual activity). Harassing behaviour can be either direct (targeted at an individual) or ambient (a general level of sexual harassment in an environment).[8]

In a 2020 UK Government survey of sexual harassment in the workplace, approximately three-quarters $(72 \%)$ of individuals reported having experienced at least one form of sexual harassment in their lifetime and $43 \%$, at least one episode within the last 12 months. The three most commonly experienced sexual harassment behaviours, were unwelcome jokes or comments of a sexual nature, unwelcome staring, and unwelcome comments of a sexual nature about body and/or clothes. The demographic groups that were significantly more likely to have experienced sexual harassment were women, young people (aged 15-34), people from an ethnic minority, individuals that identified as lesbian, gay or bisexual, and those with disabilities. The majority of individuals (75\%), who had experienced sexual harassment, felt that at least one of the nine protected characteristics (as defined in the 2010 Equality Act) was a contributory factor. Even two thirds of female soldiers in the highly trained and regulated British Army have reported sexual harassment including assault. [9]

\section{Sexual Harassment \& Discrimination}

Sexual harassment is a form of discrimination and stems from structural inequality, which comprises various forms of economic, social, religious, and political inequality ingrained in society. Gender-based discrimination intersects with ethnicity, socioeconomic status, disability, age, geographic location, gender identity and sexual orientation, among others. Structural inequality is often understood as an aggregate, cumulative product of historical wrongs, legal or policy decisions, and governmental inactions.[10]

A century after the suffragette movement, women continue to languish below their deserved status in every domain of society from pay gap [11,12] to domestic violence [13]. This divergence is exhibited even in the highest achieving global roles - such as in a study analysing the gender disparity of Nobel Laureates since 1901, found that only $6.2 \%$ of women have ever received this coveted prize, and only 23 women have received a prize in Medicine, Physics or Chemistry. [14] In the context of numerous examples of sexual discrimination, of persecution, denial of basic human rights of education, health and liberty, of rights of inheritance [15] - the achievements by women such as Hillary and Chandi are exceptional.

Often, the conversations about sexual harassment talks about women, as a single entity, whose experiences are all the same, yet women are not a homogenous group. The experience of women from diverse backgrounds or groups and with a range of protected characteristics is significantly different. To really understand the root causes of sexual harassment, we need to view the problem through an intersectional lens.[16] 


\section{High risk settings}

The characteristic environments most associated with higher rates of sexual harassment are (a) male-dominated workplaces, a power imbalance in favour of men, male dominated work settings such as toxic masculine behaviours and (b) an organisational climate that fosters gender nonconformity, encourages normalisation or tolerance of sexual harassment, a culture of silence driven by fear or persecution and hierarchical, autocratic leadership lacking in compassion. [17] The 2018 Australian National Survey[18] found that the majority of individuals were sexually harassed by a single perpetrator, most $(79 \%)$ were male, more than half $(54 \%)$ were aged 40 or older and commonly a coworker employed at the same level (27-35\%).

Some workplace settings with a higher risk of experiencing sexual harassment are;

- the information, media, telecommunication, arts and recreation industry,

- those which are primarily male-dominated (for example, the construction and mining industries),

- those which involve a high level of contact with third parties, including customers, clients or patients (for example, the retail and hospitality sectors, and the health care and social assistance industry);

- those that are organised in strict hierarchical structures (for example, in police organisations, the uniformed forces, and the medical as well as legal professions).

- settings with established gender inequality, therefore a symptom of social inequalities, sociocultural gender and power differentials.[19]

- healthcare, where this is most prevalent in male dominated specialties such as surgery, areas with increased personal contact such as when performing procedures together and areas of established historical role inequalities or differentials, such as in nursing and midwifery.

The healthcare workplace is typically hierarchical, carrying high stakes, consisting of toxic competitive professional aspirations often allowing an environment of harassment to be propagated. Within healthcare, female nurses report the highest levels of sexual harassment up to $87 \%$, including $41 \%$ perpetrated by their physician colleagues.[20] It is acknowledged that the interaction of different aspects of one's identities affects the ways that harassment is perpetrated and often occurs together with other forms of discrimination such as racism, homophobia, xenophobia or against those with disability. Younger workers (approximately aged 18-29 years), often at the beginning of their careers, in temporary work, in lower positions of power - are more prone to harassment, less confident to speak out and thus experience the highest levels of sexual harassment. In the context of healthcare, these are likely to be early career professionals who fear the impact on stressful and often arbitrary progression assessments such as their review of competency or career progression, the possibility of an increased length of training, the impairment of their reputation and confidence and diminished prospects of future employment.

\section{Impact of Intersectionality}

Crenshaw in 1989 [21] described that a person's social and political identities coalesce or 'intersect' with each other to determine their experiences of privilege or discrimination including harassment- perhaps the first description of intersectionality. It is a complex, cumulative way in which the effects of multiple forms of discrimination (such as racism, sexism, and classism) combine, overlap, or intersect thus determining the experiences of marginalised individuals or groups. [22] An individual's experience of harassment in the workplace is impacted by the intersections of their ethnic background, culture, religion, sexual and gender identity, disability and social status. [23] 
Though there is still limited research on the impact of intersectionality, the US National Academies reported that Black, Asian and minority ethnic (BAME) women were more likely to feel unsafe to experience verbal racial harassment and much less likely to report this compared to white women.[24] [25] Relative to other social identities, religious identity can lead to higher levels of harassment. [26] The \#MeToo movement (conceived in 2006 by Tarana Burke), brought visibility to sexual assault, harassment, and abuse of power. It illuminated how even those women with significant amounts of social, political, and economic power experience gender-based harassment that, until now, had gone unreported for fear of social and professional repercussions. The celebrity advocacy in 2017, drew attention to how sexual harassment was endemic in most societies, was differentiated by historical and material structures of race, gender, sexuality, citizenship, or class - highlighted the contribution to deepening gender inequality in workplaces, [27][28][29] occupational and psychological outcomes.[30]

\section{Immigration}

A large proportion of healthcare workforce have immigrated from their native countries or cultures to Western societies which encompass a different set of social and cultural norms. Immigrant status is an important determinant in perpetuating structural inequalities as well as sexual harassment. [31] The power and privilege relationships between men and women are different across societies around the world where women may not be empowered to react to men including their sexual advances. Women from different ethnic backgrounds may be oblivious in unfamiliar social or cultural settings, different linguistic interpretations of cues, be isolated in their support systems and be unsure of how to react during uncomfortable situations.[32] They are often viewed differently or misunderstood by their colleagues and this compounds their vulnerability.

\section{Solutions}

\section{Policies}

Tackling structural inequality requires remedies that go beyond incremental approaches focussed on individuals and include transformation of the organisational and societal ethos by interventions supported by affirmative policies and courageous, compassionate leadership. [8] Most organisations believe in the power of developing relevant policies including gender mainstreaming. [33] Since 1997, the UN Economic and Social Council has incorporated this approach "assessing the implications for women and men of any planned action, including legislation, policies, or programmes". There is a need for society, governments and institutions to create policies and procedures to promote diverse, inclusive, and respectful environments. Institutions must encourage an organisational culture that fosters an open environment, minimises the negative consequences of frictions that are inevitable with culture change and recognise that progress from diversity is maximised when reflected in higher leadership positions. Policy and programmatic interventions to improve equity, diversity, culture, and workplace environment may lead to a decrease in gender pay disparity, a balanced workforce and a decrease in inappropriate behaviours between co-workers. [24] However, there is almost no real evidence yet to support the effectiveness of most major policy-based preventive measures, in fact the much of these interventions including research on sexual harassment is believed to lack theoretical, longitudinal, qualitative and intersectional approaches or perspectives.[23]

\section{Training}

Education and training often focussed on the individual as a remedial measure or as team learning is a commonly employed intervention to tackle sexual harassment in workplaces. Ideally to understand the stages of sexual harassment from a victim's perspectives may help to design and target specific interventions. Yet there is 
little evidence of its longitudinal effectiveness or sustainability. Eatough et al., believe 'the burden to combat sexual harassment should not rest on training the victim but should involve preventative and educational training for both genders, as both genders are victims, bystanders, and perpetrators.'[34] Understanding the stages of sexual harassment from a victim's perspective helps to design and target specific interventions. These are: a perceived sexually harassing act, sensemaking and decision-making, resistance through voice/silence, and perceived organisational response. [35]

Contextual learning that embeds factors such as location, the prevalent culture, the work environment, the social norms, and the mentalemotional states of the individual are more likely to be successful. [34] However, a single training event is unlikely to change behaviour nor learning maintained over time.[36] Some training interventions achieve learning transfer [37] and that deep learning can affect the larger systems of belief and behaviour. [38] This can be completed by coaching or mentoring with the aim of generating a form of retrieval practice [39], reinforcement by use of local cases, roleplay to practice acceptable behaviour norms, engagement in reflection and development of improvement strategies as well as an analysis of purpose. Discussion about sexual harassment can elicit a range of emotions, especially for those who have been victims, witnesses, confidants, or perpetrators and disagreements which can be both distracting and disruptive. Therefore, to be effective such training needs to ensure psychological safety and space for differing individual experiences within the learning environment to be heard and reflected on. Expert facilitation is essential for success.

Table. 1 Principles and approaches to primary prevention that may be relevant to future interventions.[40][24]

\begin{tabular}{|l|l|}
\hline $\begin{array}{l}\text { Addressing intersecting forms of harassment and } \\
\text { discrimination }\end{array}$ & $\begin{array}{l}\text { For example, relating to a person's race, sexual } \\
\text { orientation or disability, ensuring that minority ethnic } \\
\text { women who are disproportionately targeted, are not } \\
\text { virtually invisible. [26][27] }\end{array}$ \\
\hline Using a holistic community-based approach & $\begin{array}{l}\text { to address different aspects of the problem across } \\
\text { multiple settings, including workplaces, media, } \\
\text { education, arts, and sports }\end{array}$ \\
\hline Encouraging bystanders to act & $\begin{array}{l}\text { Engaging men and boys proactively in increasing } \\
\text { awareness of the issues and acting to prevent such } \\
\text { actions among their peers [28] }\end{array}$ \\
\hline $\begin{array}{l}\text { Data } \\
\text { grassroots individuals and their networks making a } \\
\text { difference; }\end{array}$ & $\begin{array}{l}\text { Monitoring survey data routinely and evaluating } \\
\text { specific measures }\end{array}$ \\
\hline Networking can change things [29] & $\begin{array}{l}\text { Robustly dealing with backlash or resistance to } \\
\text { prevention initiatives.[17] }\end{array}$ \\
\hline $\begin{array}{l}\text { Advocacy and activism } \\
\text { management or organisations. }\end{array}$ \\
\hline
\end{tabular}


Box. 1 Training intervention necessitate psychological safety measures: coaching alone or as supplement

\begin{tabular}{|c|c|}
\hline Trainer & Psychological safety \\
\hline Training of the trainer on psychological safety & confidentiality provisions, small group size \\
\hline $\begin{array}{l}\text { Coaching, either alone or as a supplement to workshop } \\
\text { training }\end{array}$ & $\begin{array}{l}\text { In coaching, } \\
\cdot \quad \text { the coach deliberately crafts a psychologically } \\
\text { safe and } \\
\cdot \quad \text { confidential relationship, similar to therapy, } \\
\cdot \quad \text { where individual beliefs, attitudes, histories, } \\
\text { and vulnerabilities can be realised., } \\
\cdot \quad \text { allowing individuals to adopt and explore } \\
\text { different perspectives } \\
\cdot \quad \text { using the individual's own pace and readiness. }\end{array}$ \\
\hline $\begin{array}{l}\text { Coaching involves } \\
\cdot \text { partnering with the coached in a thought- } \\
\text { provoking and } \\
\cdot \quad \text { creative process with } \\
\cdot \text { the goal should be to maximise the coached } \\
\text { individual's personal and professional potential. }\end{array}$ & $\begin{array}{l}\text { Coaches to maintain the strictest levels of } \\
\text { confidentiality except under specific circumstances as } \\
\text { required by law. }\end{array}$ \\
\hline $\begin{array}{l}\text { Coaching also allows for } \\
\text { · the exploration of emotionally driven decisions } \\
\text { related to this issue, such as men's reluctance to } \\
\text { mentor women due to fear of accusation } \\
\text { (Ubelacker, 2018). }\end{array}$ & $\begin{array}{l}\text { - Allows for private discussion of one's } \\
\text { experience as a victim, } \\
\text { · a witness or bystander of an incident, } \\
\text {. a confidant, or } \\
\text { - a perpetrator (intentional or unintentional). }\end{array}$ \\
\hline
\end{tabular}

\section{Conclusions}

There is a significant overlap in sexual harassment and gender-based discriminationboth being a manifestation of power imbalance, inherent structural inequalities and societal inaction or acceptance. This form of systematic discrimination, harassment and abuse is also widely prevalent in healthcare, as in the wider society. However change is possible and there are powerful role models like Hilary and Chandi who are breaking through. The \#MeToo movement demonstrated the power of grassroots individuals and their networks making a difference; Their mantra included starting small, using every individual sphere of influence, the power of local activism, driven by compelling storytelling and using the power of social networks. [41]

At societal and organisational level, there is a need to implement the policies and laws that exist but to combine this with total commitment, compassionate leadership, accountability and holistic solutions which address the imbalance, social inequalities, the legacy power gradient and deep-rooted bias. This work must be led from both ends of the organisation; the grassroots and the top leadership and must include the intersectionality of multiple contributors to discrimination or harassment. The first step in tackling this issue is being honest, acknowledging the issue at hand and to apologise.

'Hope begins in the dark, the stubborn hope that if you just show up and try to do the right thing, the dawn will come' Anne Lamott 


\section{References}

1 The Inside Story of the African American Explorer Who was the First Man to Stand on Top of the North Pole. Adventure.

2014.https://www.nationalgeographic.com/advent ure/article/the-legacy-of-arctic-explorer-matthewhenson (accessed 5 Jan 2022).

2 Trailblazer in the Arctic: A Tribute to the First African American to Reach Both Poles. The Arctic Institute.

2020.https://www.thearcticinstitute.org/trailblaze r-arctic-tribute-first-african-american-reach-bothpoles/ (accessed 4 Jan 2022).

3 Fleming S, Fisher R. Sexual assault in surgery: a painful truth. Bulletin 2021;103:282-5. doi:10.1308/rcsbull.2021.106

4 rcsbull.2022.pdf.

https://publishing.rcseng.ac.uk/doi/pdf/10.1308/r csbull.2022.5?download=true (accessed 4 Jan 2022).

5 Borumandnia N, Khadembashi N, Tabatabaei M, et $a l$. The prevalence rate of sexual violence worldwide: a trend analysis. BMC Public Health 2020;20:1835. doi:10.1186/s12889-020-09926-5

6 Gender: definitions. https://www.euro.who.int/en/healthtopics/health-determinants/gender/genderdefinitions (accessed 31 May 2021).

7 Sex Discrimination Act 1975. https://www.legislation.gov.uk/ukpga/1975/65/e nacted (accessed 4 Jan 2022).

8 National Academies of Sciences E, Affairs P and G, Committee on Women in Science E, et al. Sexual Harassment Research. National Academies Press (US) 2018.

https://www.ncbi.nlm.nih.gov/books/NBK519455 / (accessed 8 Jan 2022).

9 Townsend M, editor MTH affairs. Two-thirds of women in UK military report bullying and sexual abuse. The Observer.

2021.https://www.theguardian.com/uknews/2021/jul/25/two-thirds-of-women-in-ukmilitary-report-bullying-and-sexual-abuse (accessed 4 Jan 2022).

10 Rahman KS. Constructing and Contesting Structural Inequality. Critical Analysis of Law

2018;5.https://cal.library.utoronto.ca/index.php/c al/article/view/29507 (accessed 8 Jan 2022).

11 Healy G, Ahamed MM. Gender Pay Gap, Voluntary Interventions and Recession: The Case of the British Financial Services Sector. British Journal of Industrial Relations 2019;57:302-27. doi:10.1111/bjir.12448

12 New data on gender pay gap in medicine. GOV.UK. https://www.gov.uk/government/news/new-dataon-gender-pay-gap-in-medicine (accessed 31 Aug 2020).

13 Frontiers | Editorial: New Perspectives on Domestic Violence: From Research to Intervention | Psychology.

https://www.frontiersin.org/articles/10.3389/fps yg.2019.00641/full (accessed 4 Jan 2022).

14 News ABC. Nobel Prize Foundation under fire for rejecting ethnic, gender quotas. $\mathrm{ABC}$ News. https://abcnews.go.com/International/nobel- prize-foundation-fire-rejecting-ethnic-genderquotas/story?id=80536436 (accessed 4 Jan 2022).

15 Bhalotra S, Brulé R, Roy S. Women's inheritance rights reform and the preference for sons in India. Journal of Development Economics 2020;146:102275. doi:10.1016/j.jdeveco.2018.08.001

16 Annese L. If We Want To Prevent Sexual Harassment, We Need To Look At Racism And Homophobia Too. https://www.refinery29.com/enau/2021/09/10662068/sexual-harassmentprevention-intersectionality (accessed 4 Jan 2022).

17 Sexual Harassment, Workplace Authority, and the Paradox of Power - Heather McLaughlin, Christopher Uggen, Amy Blackstone, 2012. https://journals.sagepub.com/doi/full/10.1177/00 03122412451728 (accessed 5 Jan 2022).

18 Everyone's business: Fourth national survey on sexual harassment in Australian workplaces (2018) | Australian Human Rights Commission. https://humanrights.gov.au/our-work/sexdiscrimination/publications/everyones-businessfourth-national-survey-sexual (accessed 4 Jan 2022).

19 Burn SM. The psychology of sexual harassment. Teaching of Psychology 2019;46:96-103. doi:10.1177/0098628318816183

20 Kahsay WG, Negarandeh R, Dehghan Nayeri N, et al. Sexual harassment against female nurses: a systematic review. BMC Nursing 2020;19:58. doi:10.1186/s12912-020-00450-w

21 Crenshaw K. Demarginalizing the Intersection of Race and Sex: A Black Feminist Critique of Antidiscrimination Doctrine, Feminist Theory and Antiracist Politics. The University of Chicago Legal Forum 1989;140:139-

67.https://heinonline.org/HOL/LandingPage?hand le=hein.journals/uchclf1989\&div=10\&id=\&page=

22 Intersectionality Definition \& Meaning - MerriamWebster. https://www.merriamwebster.com/dictionary/intersectionality (accessed 8 Jan 2022).

23 Bondestam F, Lundqvist M. Sexual harassment in higher education - a systematic review. European Journal of Higher Education 2020;10:397-419. doi:10.1080/21568235.2020.1729833

24 Golden SH. The perils of intersectionality: racial and sexual harassment in medicine. J Clin Invest 2019;129:3465-7. doi:10.1172/JCI130900

25 \#MeToo in EM: A Multicenter Survey of Academic Emergency Medicine Faculty on Their Experiences with Gender Discrimination and Sexual Harassment - PubMed https://pubmed.ncbi.nlm.nih.gov/32191183/ (accessed 4 Jan 2022).

26 Ryan AM, Gardner DM. Religious Harassment and Bullying in the Workplace. In: D'Cruz P, Noronha E, Caponecchia C, et al., eds. Dignity and Inclusion at Work. Singapore: : Springer 2021. 463-87. doi:10.1007/978-981-13-0218-3_16

27 Get To Know Us | History \& Inception. me too. Movement. https://metoomvmt.org/get-to-knowus/history-inception/ (accessed 4 Jan 2022).

28 Sexual Violence and Intersectionality. Center for the Study of Women. 
https://csw.ucla.edu/cswresearch/sexual-violenceand-intersectionality/ (accessed 4 Jan 2022).

29 Calafell BM. "Did It Happen Because of Your Race or Sex?": University Sexual Harassment Policies and the Move against Intersectionality. Frontiers: $A$ Journal of Women Studies 2014;35:75-95. doi:10.5250/fronjwomestud.35.3.0075

30 Buchanan NT, Fitzgerald LF. Effects of racial and sexual harassment on work and the psychological well-being of African American women. Journal of Occupational Health Psychology 2008;13:137-51. doi:10.1037/1076-8998.13.2.137

31 Agudelo-Suárez AA, Ronda-Pérez E, Gil-González D, et al. The effect of perceived discrimination on the health of immigrant workers in Spain. BMC Public Health 2011;11:652. doi:10.1186/1471-2458-11652

32 Murphy J, Samples J, Morales M, et al. "They Talk Like That, But We Keep Working": Sexual Harassment and Sexual Assault Experiences Among Mexican Indigenous Farmworker Women in Oregon. J Immigrant Minority Health 2015;17:1834-9. doi:10.1007/s10903-014-9992-z

33 Gender disparities in clinical practice: are there any solutions? Scoping review of interventions to overcome or reduce gender bias in clinical practice | International Journal for Equity in Health | Full Text.

https://equityhealthj.biomedcentral.com/articles/ 10.1186/s12939-020-01283-4 (accessed 23 Jan 2022).

34 Evidence-based recommendations for improved design of sexual harassment training | Industrial and Organizational Psychology | Cambridge Core. https://www.cambridge.org/core/journals/industr ial-and-organizationalpsychology/article/abs/evidencebasedrecommendations-for-improved-design-of-sexualharassmenttraining/10A30EF219E4A459E940A7FAAD88AEB
8 (accessed 23 Jan 2022).

35 Richardson BK, Taylor J. Sexual Harassment at the Intersection of Race and Gender: A Theoretical Model of the Sexual Harassment Experiences of Women of Color. Western Journal of Communication 2009;73:248-72. doi:10.1080/10570310903082065

36 Medeiros K, Griffith J. \#Ustoo: How I-O psychologists can extend the conversation on sexual harassment and sexual assault through workplace training. Industrial and Organizational Psychology 2019;12:1-19. doi:10.1017/iop. 2018.155

37 The transfer of training: what really matters Grossman - 2011 - International Journal of Training and Development - Wiley Online Library. https://onlinelibrary.wiley.com/doi/10.1111/j.146 8-2419.2011.00373.x (accessed 23 Jan 2022).

38 Wickelgren WA. Human Learning and Memory. ;:33.

39 Evidence-based recommendations for improved design of sexual harassment training | Industrial and Organizational Psychology | Cambridge Core. https://www.cambridge.org/core/journals/industr ial-and-organizationalpsychology/article/abs/evidencebasedrecommendations-for-improved-design-of-sexualharassmenttraining/10A30EF219E4A459E940A7FAAD88AEB 8 (accessed 23 Jan 2022).

40 Worthen MGF, Wallace SA. Intersectionality and Perceptions About Sexual Assault Education and Reporting on College Campuses. Family Relations 2017;66:180-96. doi:10.1111/fare.12240

41 Five lessons from the founder of the Me Too movement | Imperial News | Imperial College London. Imperial News. https://www.imperial.ac.uk/news/231994/fivelessons-from-founder-me-too/ (accessed 4 Jan 2022). 